SCIREA Journal of Environment

http://www.scirea.org/journal/Environmental

May 24, 2021

Volume 5, Issue 3, June 2021

\title{
Bioacoustic analysis: A tool in discriminating the Mindanao Island river toads, genus Ansonia (Amphibia: Anura: Bufonidae) species complex
}

\author{
Nelieta B. Arnejo Bedoya \\ Department of Environmental Studies, College of Forestry and Environmental Studies \\ Mindanao State University-Main Campus, Marawi City \\ Email:nel_mcbed@yahoo.com
}

\begin{abstract}
Genus Ansonia of the family Bufonidae, order Anura of amphibians in the Philippines is found only in Mindanao Island. Current classification bares only two species, A. mcgregori and $A$. muelleri. However, the differences represent individual variation rather than species differentiation. Otherwise proven, these species must be considered conspecific. Thus, there is a need for more evidence other than the morphological characteristics. Bioacoustics, aside from molecular analysis, now provides for distinguishing species which cannot be separated by morphological traits. Moreover, characterization of these species complex as to bioacoustics is still dearth or has not been established yet. This study recorded vocalizations of the Ansonia spp. in eight rivers in Mindanao. Analyses of the recorded vocalizations made use of oscillograms (waveforms), audiospectograms (sonograms), and results of the Fast Fourier Transformation (FFT: frequency spectrum) for a variety of temporal and spectral characters using Raven Pro 1.4 for Windows (2011) considering some ecological and morphological features. Results bared that call duration, interval, calling rate, number of calls
\end{abstract}


per minute and peak call frequency varied where some of which were influenced by some ecological factors and body sizes. These could serve as a basis for reassessment on the classification of Ansonia spp.

Keywords: conspecific, call characteristics analysis

\section{INTRODUCTION}

The Philippine archipelago, previously thought of as having an insignificant herpetofauna, is now recognized as one of the most important centers of amphibian and reptile diversity in Southeast Asia (Diesmos et al. 2002), harboring an estimated total of 102 indigenous and 5 or 6 introduced species of amphibians (Stuart and Bain 2008), 98 species of which are frogs, which can be raised to around 131 to 142 taxa. This estimate could even be higher with pending number of undescribed anurans having cryptic/complex species like Ansonia, a Mindanao Island endemic and vulnerable (Frost 2009).

There are two known species of Ansonia: A. muelleri and A. mcgregori. Established evidence suggests differences representing individual rather than species differentiation. Without significant evidence to the contrary, A. mcgregori must be considered conspecific with $A$. muelleri. Thus, there is a need for more evidence, other than the morphologically-based established characteristics, using molecular and bioacoustics analyses. Bioacoustics often offer the key for distinguishing complex species difficult to differentiate, by morphological traits (Malkmus et al. 2002), though not very widely utilized yet. Hence, result of this study can serve as baseline as to bioacoustics characterization of Ansonia species as publications of this is wanting if not absent. Moreover, anuran biodiversity estimation can also be improved.

The abovementioned contentions suggest for a reassessment of the identity and conservation status of the genus Ansonia species complex. Hence, this study utilized bioacoustic analysis tool. Recorded and analyzed vocalizations of the species making use of oscillograms/waveforms, audiospectograms/sonograms, and results of the Fast Fourier Transformation for a variety of temporal and spectral characters are presented where significant differences on the vocalizations of these species were determined, and as affected by some ecological and morphological features, trying to ascertain species boundaries/differentiations. 


\section{MATERIALS AND METHODS}

\section{Study Sites}

Call recordings of Ansonia species were made onsite at eight rivers (Fig. 1) in Northern Mindanao: Inobulan River of Mt. Balatukan, Gingoog City ; Clarin River, east of Mt. Malindang, Ozamis City, and Kabangahan River of Mt. Gabunan, Iligan City; Central Mindanao in Kirundong River of Mt. Apo and Mt Linanggasan, at Magpet, North Cotabato; Southern Mindanao in Kanloslo River of Mt. Busa, Kiamba, Sarangani Province; and Western Mindanao: Moradji River, west of Mt. Malindang, Josefina; Murias River of Mt. Murias, Lourdes, Pagadian City; and Maragang River of Mt. Timolan, Tigbao, all in Zamboanga del Sur.

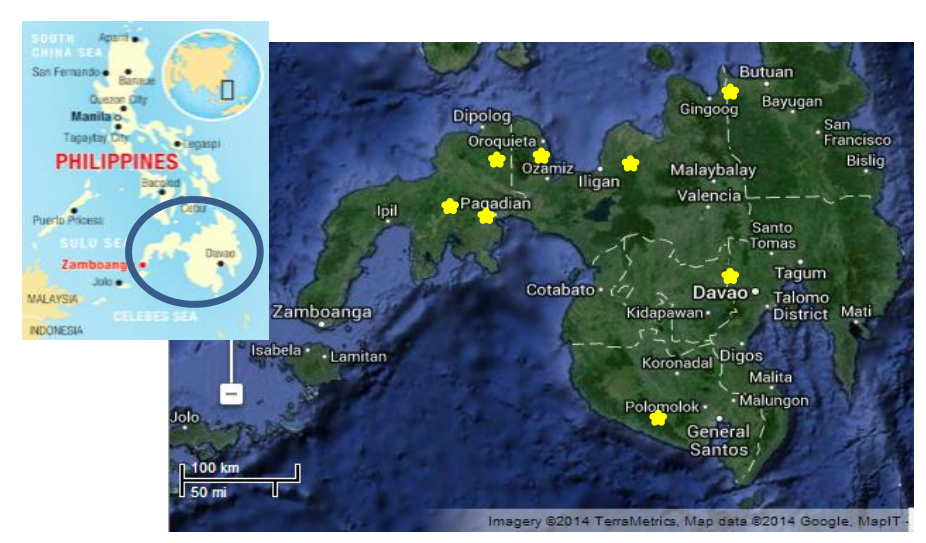

Figure 1. Location map of the rivers where calls of Ansonia spp. were recorded.

\section{Data Collection}

Ansonia species were searched along rivers by opportunistic day and night sampling. The calls (of at least 4 individuals per river) were recorded for a maximum of 15 minutes at distances 0.5 - 2.0 meters using a Tascam DR-1 Portable Solid State Recorder with a WAV recording resolution of $44100 \mathrm{~Hz}$, using a uni-directional external microphone to minimize unwanted sounds (Fig. 2). 


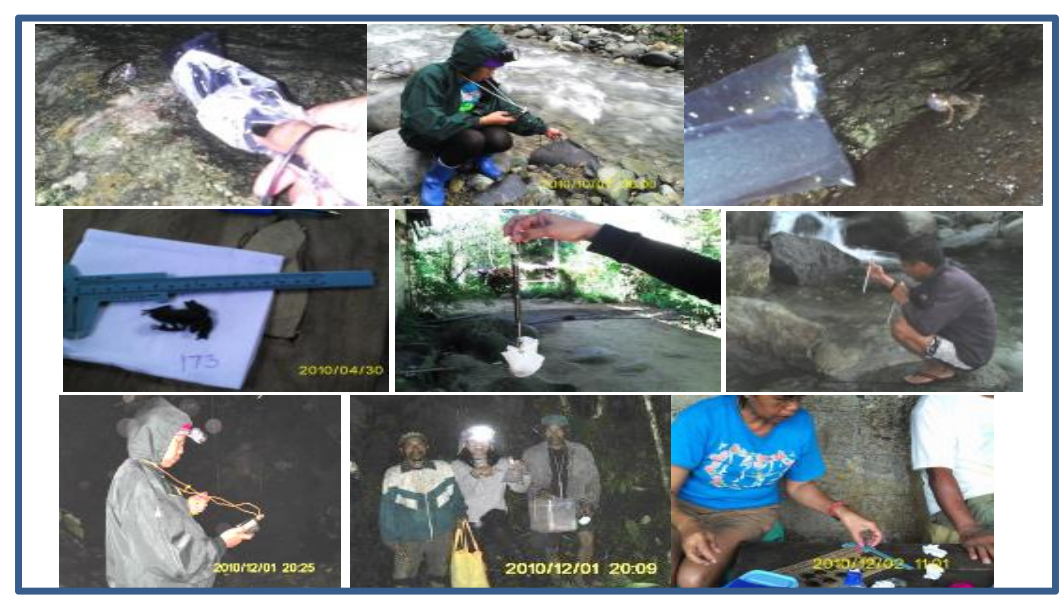

Figure 2. Field sampling, recording, voucher specimen preparation and body sizes determination.

Out of the 15-minute recording per toad, a 5-minute call was selected and sliced, and further dissected into minute-call slices for bioacoustic analysis using Raven Pro 1.4 for Windows (2011) in wave sound file format with a sample rate of $44100 \mathrm{~Hz}$, encoding 24-bit. Fast Fourier Transformation (FFT: frequency spectrum: relative amplitude (dB) vs frequency, in $\mathrm{Hz}$ ), oscillogram (relative amplitude vs time in sec) and an audio-spectrogram (sonogram: Frequency in $\mathrm{Hz}$ vs time) were defined (Fig. 3), making five replications. Ecological parameters like elevation, water and ambient temperatures, relative humidity of the rivers sampled, and perch heights of calling toads were also recorded using Global Positioning System (GPS), mercurial laboratory thermometer, digital thermal-hygrometer and meter stick, respectively. Body weight (Pesola weighing scale) and snout-vent length or SVL (vernier caliper) of Ansonia spp. were measured.

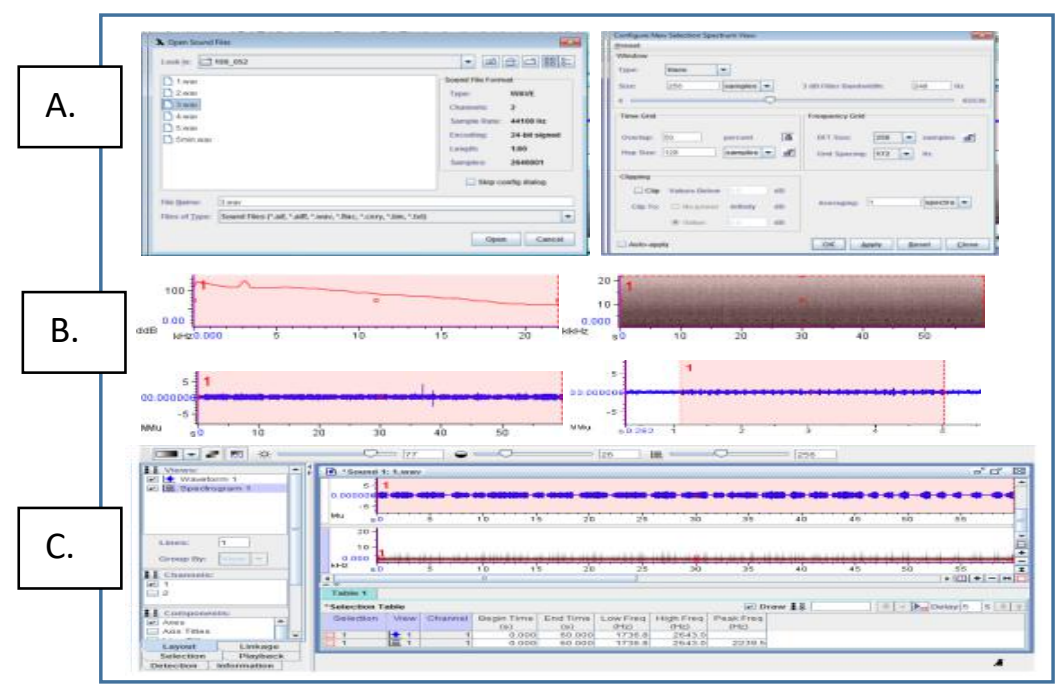

Figure 3. A: The sound file format (Raven Pro 1.4) of each 1-min (60-sec) length call (left) and settings in configuring new selection spectrum view (right). B: Sample of a Fast Fourier 
Transformation (FFT: frequency spectrum:), oscillogram/waveform and an audiospectrogram/sonogram diagrams. C: A sample of the peak frequency measurement.

\section{Data Analyses}

Simple descriptive statistics described the calls and body sizes of Ansonia spp. so with the ecological features of the rivers. Analysis of variance (ANOVA) facilitated significant difference determination between/within group means. R-squared or the coefficient of multiple determinations for multiple regressions as a statistical measure of how close the data are to be fitted in regression line. Statistical Package for the Social Sciences (SPSS) version 21 and PAleontological STatistics (PAST) version 2.17 programs were used.

\section{RESULTS AND DISCUSSION}

\section{The Ansonia species in the sampling sites}

Two species of Ansonia endemic to Mindanao Island, referred to as slender stream toads, are recognized as A. mcgregori and A. muelleri (Diesmos, et al. 2004, Frost 2009) considering morphometric. Based on the recent molecular study of Sanguila et al. 2011, those from the rivers of Inobulan, Kabangahan, Kanloslo and Kirundong can be likely classified as $A$. muelleri. Those in the rivers of Clarin, and Moradji are possibly A. mcgregori, while those from Murias and Maragang could be Ansonia sp.2.

The Ansonia species in the study exhibited a general mean weight of $2.92 \mathrm{~g}$ (1.48 to 5.00 grams) with a mean SVL of $32.49 \mathrm{~mm}$. (24.29mm. to $39.70 \mathrm{~mm})$. Those classified as $A$. muelleri are quite smaller $(2.54 \mathrm{~g}, 31.18 \mathrm{~mm})$, except those from Kabangahan $(4.26 \mathrm{~g}, 36.9 \mathrm{~mm})$, compared to those assumed as A. mcgregori $(3.29 \mathrm{~g}, \mathrm{SVL}=33.8 \mathrm{~mm})$. These species inhabited rivers located in areas with elevations ranging from 209 to 1442 masl, relative humidity percentages of 74.67 to 90.06 , river water temperatures of 16 to $25{ }^{\circ} \mathrm{Celcius}$ and 19 to 29.90 ${ }^{0}$ Celcius ambient temperatures. Prevailing landuses along rivers include agro-ecosystem landuse with coconut, fruit trees and corn/rice paddy (Clarin, Moradji and Murias Rivers), transition to low montane forest (Kirondong, Kanloslo and Inobulan Rivers), and transition to low dipterocarp forest (Kabangahan and Maragang Rivers).

\section{Advertisement call characteristics of Ansonia species}

Advertisement call of Ansonia species is used to be emitted by the males to primarily attract conspecific females who are ready to mate, and serves as a mechanism in maintaining 
reproductive isolation from other sympatric species (Roy 1994). The calling activity was heard after sunset to dawn and more so during a drizzle and after a rain, if not near noisy fast flowing waters during the early morning or late afternoon, lasting for as long as more than an hour while perched on a wet substrate, mostly stones, along the rivers. Before an advertisement call was emitted, a territorial call was first made to announce his presence while looking for females nearby. Oftentimes, several males simultaneously emitted calls at shorter distances especially after a rain, competing for female's attention. Advertisement call emitted by Ansonia species is shown below (Fig. 4).
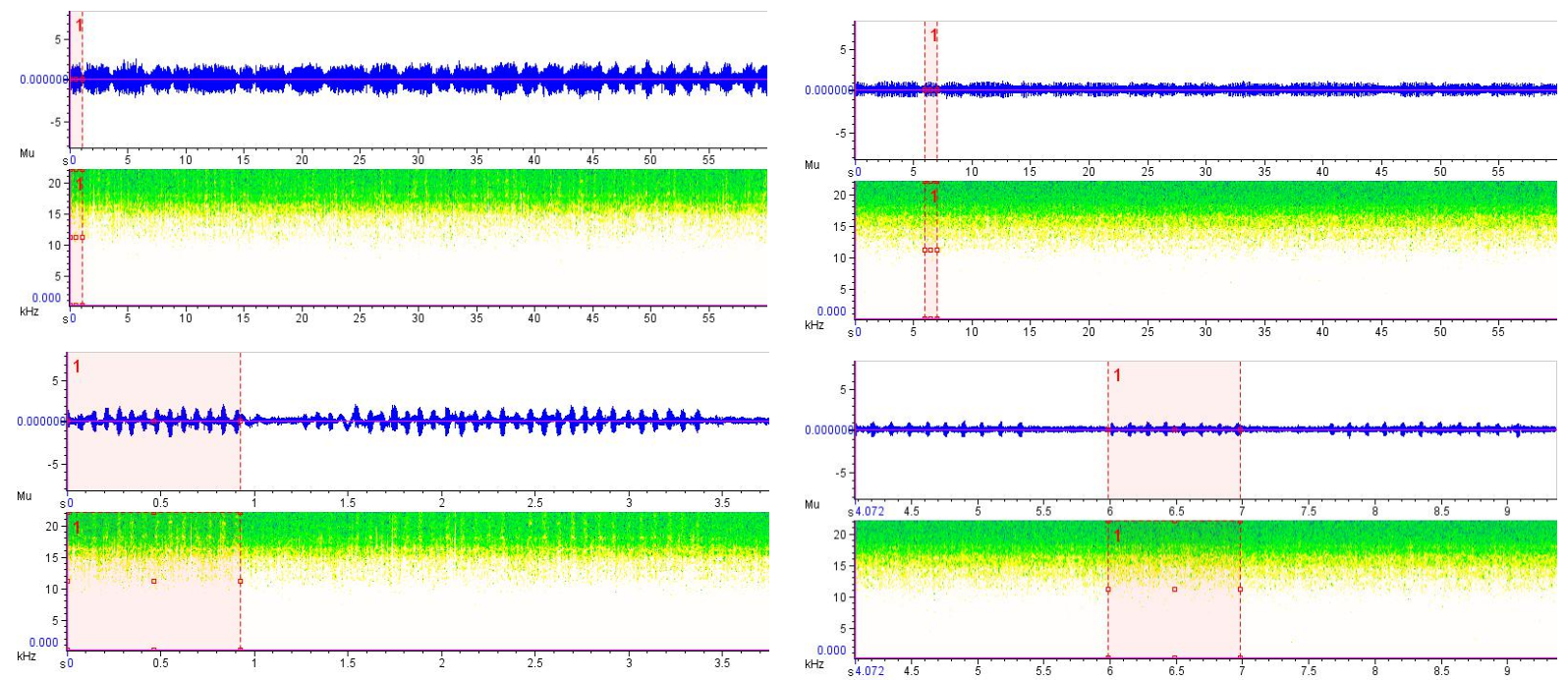

Oscillogram and spectrogram of Ansonia sp. from Clarin River (144_028 1.wav call1)

Oscillogram and spectrogram of Ansonia sp. from Inobulan River (096_010 2.wav call2)

Figure 4. Advertisement call samples of Ansonia species recorded during sampling.

Call duration (sec). Call duration is the duration from the beginning of a call to its end, measured in seconds (Roy and Elepfandt 1993). The durations of the advertisement call of Ansonia spp. range from 0.68 to $21.77 \mathrm{sec}$. The longest mean call duration was emitted by stream toads at Inobulan River ranging from 1.1-21.77 sec $(5.18 \pm 5.94 \mathrm{sec}, \mathrm{n}=13)$. The shortest $(1.73 \pm 0.65 \mathrm{sec}, \mathrm{n}=5)$ was from those in Kabangahan River with 1.05-2.65 sec. ANOVA showed no significant difference $(\mathrm{F}=1.69, \mathrm{df}=7, \mathrm{p}=0.13)$ between/within group means of call duration. However, the means of call duration and the weight of those toads in Maragang was found significantly correlated $\left(\mathrm{R}^{2}=0.638, \mathrm{p}=0.013\right)$. This relationship is also true between call duration and SVL from those in Kirundong $\left(\mathrm{R}^{2}=0.867, \mathrm{p}=0.026\right)$ and Maragang $\left(\mathrm{R}^{2}=0.793, \mathrm{p}=0.037\right)$. 
Call interval (sec). Call interval refers to the time from end of a call to the beginning of the next call, measured in seconds (Roy and Elepfandt 1993). The call intervals vary from 0.27 to $52.05 \mathrm{sec}$. The longest mean call interval was exhibited by the stream toads from Inobulan River with a range of 0.57-52.05 (7.61 \pm 14.02$)$ sec. and the shortest from Kanloslo River at 0.30-0.93 (0.57 \pm 0.28$)$ sec. ANOVA showed no significant difference $(F=1.09, \mathrm{df}=7, \mathrm{p}=0.38)$ between/within group means of call interval. Nevertheless, this feature is highly significantly associated with elevation and with air temperature from those in Kirundong $\left(\mathrm{R}^{2}=0.968\right.$, $\mathrm{p}=0.006)$ and with air temperature from those in Moradji $\left(\mathrm{R}^{2}=0.977, \mathrm{p}=0.01\right)$.

Calling rate (number of calls per sec). Calling rate refers to the (total number of calls -1 ) divided by the time from beginning of the first call or pulse to beginning of last (Brown et al. 2002). The calling rates of the Ansonia species vary from 0.07 to 0.83 . Those toads in Kabangahan River had the highest mean number $(0.34-0.56,0.46 \pm 0.9)$ of calls per second, while Inobulan River had the lowest $(0.07-0.48,0.26 \pm 0.12)$. These mean variations are found not statistically significant $(\mathrm{F}=0.504, \mathrm{df}=7, \mathrm{p}=0.83)$ but are significantly associated with elevation $\left(\mathrm{R}^{2}=1.0, \mathrm{p}=0.015\right)$, with water temperature $\left(\mathrm{R}^{2}=1.0, \mathrm{p}=0.017\right)$ in Kabangahan, and with relative humidity in Moradji $\left(\mathrm{R}^{2}=0.977, \mathrm{p}=0.021\right)$. This is also significantly correlated with the weight $\left(\mathrm{R}^{2}=0.793, \mathrm{p}=0.019\right)$ and $\operatorname{SVL}\left(\mathrm{R}^{2}=0.793, \mathrm{p}=0.037\right)$ of those in Moradji.

Number of calls per minute. Number of calls is determined per minute. The recorded least number of calls is 0.2 and the most number is 50.0. Those in Murias River had the most number $(15.40-40.20,25.10 \pm 9.40)$ of calls per minute. Inobulan River toads had the least (0.2-19.8, 5.66 \pm 5.16$)$. Variations revealed highly significant differences $(\mathrm{F}=5.34, \mathrm{df}=7$, $\mathrm{p}<0.01)$ between/within the mean number of calls of Inobulan and Moradji ( $p=0.02)$, Inobulan and Murias $(p=0.0007)$, and Kirundong and Murias $(p=0.006)$ rivers. This feature is significantly associated with the weights of those from Moradji $\left(\mathrm{R}^{2}=0.897, \mathrm{p}=0.03\right)$.

Peak Call Frequency. Of the call characteristics like number, duration, interval, rate and frequency, anurans recognize individuals of the same and different species by their dominant or peak call frequency. Peak or dominant call frequency refers to the frequency with maximum intensity (Trepanier, Lathrop and Murphy 1999). Frequency is the amount of complete waves every second that produce sound or it is the speed of the vibration. This determines the pitch of the sound. Peak call frequencies of the Ansonia spp. found in the sampled rivers were noted to range from 2067.2 to $3100.8 \mathrm{~Hz}$. The highest $(3100.8 \mathrm{~Hz})$ was recorded at Kirundong and Inobulan Rivers. However, Ansonia spp. calling at Kirundong River, generated the highest mean peak frequency of 2756.2-3100.8 $(3001.05 \pm 119.315) \mathrm{Hz}$, 
with the maximum intensity and the highest pitch call. In contrast, those from Kabangahan River called with the least intensity having a mean peak call frequency of only 2067.2-2239.5 (2145.52 \pm 89.9807$) \mathrm{Hz}$. ANOVA revealed highly significant mean differences between/within peak call frequencies of Ansonia spp. between Inobulan with Clarin, Kanloslo, Kabangahan, Maragang, Murias and Moradji $(\mathrm{p}<0.01)$, Clarin with Kirundong, Kabangahan, Maragang and Moradji $(\mathrm{p}<0.01)$, Kirundong with Kanloslo, Kabangahan, Maragang, Murias and Moradji $(\mathrm{p}<0.01)$, Kanloslo with Kabangahan, Maragang, Moradji and Murias $(\mathrm{p}<0.01)$, Kabangahan with Maragang, Moradji and Murias $(\mathrm{p}<0.01)$, Maragang with Murias $(\mathrm{p}<0.01)$, and Murias with Moradji $(\mathrm{p}<0.01)$.

Variations on the call characteristics of Ansonia species in various rivers sampled could be attributed to the morphological, ecological and social (the presence of female counterparts) settings, as observed. These are also parallel to some results of related studies (Brown, Foufopoulos and Richards (2006), Preininger, Bockle and Hodl (2007), Hsu, Kam and Feller (2006), Trepanier, Lathrop and Murphy (1999) and Bosch and De la Riva (2004), among others.

\section{CONCLUSION}

Anuran advertisement or mating call is now widely considered an important character for species recognition and discrimination. Bioacoustic analysis as a tool for discriminating cryptic and complex species within anurans facilitates production of total evidence together with the use of morphometric and molecular phylogenetic analysis. It can provide a great advantage to generate data for taxonomists towards a more realistic estimate of anuran biodiversity, though field works are difficult and really grueling. Establishment of the differences on the call characteristics of Ansonia species could shed light on the complexity of the species not shown through morphology. These data can aid in strengthening species differentiation already offered by molecular means. The significant differences on the number of calls and peak call frequencies may help unravel Ansonia species complexity as anurans recognize individuals of the same and different species importantly with the latter. With these, validation can be done with the clustering made through morphometric and molecular evidences. 


\section{RECOMMENDATION}

The use of bioacoustics analysis must be made widespread in differentiating cryptic/complex species in anurans. Its use can help bridge the gaps in biodiversity estimation of anuran species. Expertise on the use of softwares for analysis need to be developed and appropriate recorders be procured. As this study is among the first on bioacoustics analysis for Ansonia species, more similar study must be undertaken for validation and for widespread sampling.

\section{Acknowledgement}

This study is made possible with the generosity of the local people who became my foster family in each of the rivers I trekked and sampled; the study leave granted by the Mindanao State University at Main Campus, Marawi City, particularly my CFES family; the funding support from CHED Scholarship Grant; the wisdom gained from Doc Rafe and Ma'am Ging; the love and support of my family; and above all to God Almighty, from Whom all of me depends.

\section{REFERENCES}

[1] Bioacoustics Research Program. 2011. Raven Pro: Interactive Sound Analysis Software (Version 1.4) [Computer Software]. Ithaca, NY: The Cornell Lab of Ornithology. Available from http://www.birds.cornell.edu/raven.

[2] Bosch, J and I. De la Riva. 2004. "Are frog calls modulated by the environment? An analysis with anuran species from Bolivia". Ca. J. Zool. 82(6):880-888 (2004) /doi.10.1139/z04-060/ @2004 NRC Canada. Accessed online: August, 2015.

[3] Brown, R. M., C. N. Dolino, E. Alcala, A. C. Diesmos, and A. C. Alcala. 2002 (2003). The advertisement calls of two endangered species of endemic Philippine frogs: Platymantis spelaeus and P. insulatus (Anura; Ranidae). The Silliman Journal. [PDF]

[4] Brown, R. M., J. Foufopoulos and S. J. Richards. 2006. "New Species of Platymantis (Amphibia; Anura; Ranidae) from New Britain and Rediscription of the Poorly Known Platymantis nexipus". Copeia, 2006 (4), pp. 674-695.

[5] Brown, R. M. and S. J. Richards. 2008. "Two new frogs of the genus Platymantis(Anura: Ceratobatrachidae) from the Isabel Island group, Solomon Islands”. Zootaxa 1888: 4768. $[\mathrm{PDF}]$ 
[6] Diesmos, A. C., A. C. Alcala, R. M. Brown, L. Afuang, G. Gee, K. Hampson, M. L. Diesmos, A. Mallari, P. Ong, D. Ubaldo and B. Gutierez. 2004. Ansonia muelleri. In: IUCN 2008. 2008 IUCN Red List of Threatened Species < www.iucnredlist.org $>$. Accessed online: January 12, 2013.

[7] Diesmos, A. C., R. M. Brown and A. C. Alcala. 2002. "New species of narrow-mouthed frog (Amphibia; Anura; Microhylidae; Genus Kaloula) from the mountains of Southern Luzon and Polilio Islands, Philippines”. Copeia, 2002 (4), pp.1037-1051.

[8] Frost, D. 2009. Amphibian Species of the World: An Online Reference, Version 5.3. http://research.amnh.org/herpetology/amphibia/references.php?id=2203. Accessed online: January 12, 2013.

[9] Hsu, M.Y., Y. C. Kam and G. M. Fellers. 2006. Temporal organization of an anuran acoustic community in a Taiwanese subtropical forest”. Journal of Zoology 269 (2006) 331-339. ISSN 0952-8369.

[10] Malkmus, R., U. Manthey, G. Vogel and J. Kosesch. 2002. Amphibians and reptiles of Mt. Kinabalu (North Borneo): North Borneo, Published by Koeltz Scientific Books. ISBN 3904-144839, 9783904144834 (Accesed online: November 10, 2013).

[11] McClelland, B. E., W. Wilczynski and M. J. Ryan. 1996. "Correlations between call characteristics and morphology in male cricket frogs (Acris crepitans)". The Journal of Experimental Biology 199, 1907-1919 (1996) 1907. Printed in Great Britain (C) The Company of Biologists Limited 1996.

[12] Preininger, D., M. Bockle and W. Hodl. 2007. "Comparison of anuran acoustic communities of two habitat types in the Danum Valley Conservation Area, Sabah, Malaysia. Salamandra 43 (3) 129-138, Rheinbach, 20 August 2007. ISSN 0036-3375. http://www.salamandrajouirnal.com

[13] Roy, D. 1994. "Development of hearing in vertebrates with special reference to anuran acoustic communication”. J. Biosci., Vol. 19, No. 5, Dec. 1994, pp629-644. Printed in India.

[14] Roy, D. and A. Elepfandt. 1993. "Bioacoustic analysis of frog calls from Northeast India". J. Biosaci., Vol. 18, No. 3, September 1993, pp381-393. Printed in India.

[15] Sanguila, Marites Bonachita, Cameron D. Siler, Arvin C. Diesmos, Olga Nuñeza and Rafe M. Brown. 2011. "Phylogeography, geographic structure, genetic variation, and potential species boundaries in Philippine slender toads". ScienceDirect. Molecular Phylogenetics and Evolution journal homepage: www.elsevier.com/locate/ympev. 
[16] Stuart, B. L. and R. H. Bain. 2008. "Amphibian species discovery in Mainland Southeast Asia”. p83 In: Stuart, S.N., Hoffmann, M., Chanson, J.S., Cox, N.A., Berridge, R, Ramani, P. and Young B.E. (Eds.) Threatened Amphibians of the World. Lynx Ediciones, Barcelona, Spain; IUCN - The World Conservation Union, Gland, Switzerland; and Conservation International, Arlington Virginia, USA. [PDF]

[17] Trepanier, T. L., A. Lathrop and R.W. Murphy. 1999. "Rhacophorus leucomystax in Vietnam with acoustic analyses of courtship and territorial calls". Asian Herpetological Research, Vol. 8, pp102-106, 1999. 